\title{
In Vivo and In Vitro Pharmacodynamics of Anthelmintic Medication Used in Sheep
}

\author{
Mihai CERNEA ${ }^{1}$, Roxana FILIP ${ }^{1}$, Raul CĂTANĂ ${ }^{1}$, Laura CĂTANĂ ${ }^{1 *}$ \\ ${ }^{1}$ University of Agricultural Sciences and Veterinary Medicine Cluj-Napoca, Faculty of Veterinary Medicine, \\ Calea Mănăștur, No. 3-5, 400372, Cluj-Napoca, Romania \\ *corresponding author: laura.catana@usamvcluj.ro
}

Bulletin UASVM Veterinary Medicine 76(2)/2019

Print ISSN 1843-5270; Electronic ISSN 1843-5378

doi:10.15835/buasvmcn-vm:2019.0020

\begin{abstract}
:
Our research aimed to evaluate the efficacy of anthelmintic treatments in sheep, as well as the resistance occurrence risk for the most commonly used substances. Anthelmintic medication efficacy was evaluated on 30 animals from a private farm, located in Sânmihaiu Almașului, Sălaj County. In vivo studies were performed by using Fecal Egg Count Reduction Test (FECRT) and testing an albendazole-based (ABZ) product. In vitro, we used Egg Hatch Assay (EHA) and Larval Development Assay (LDA) for albendazole (ABZ), mebendazole (MBZ), fenbendazole (FBZ), thiabendazole (TBZ) and ivermectin (IVM) (only for LDA). FECRT showed that intestinal nematodes developed resistance phenomena against the ABZ-based product, with an extensivity of $80 \%$ at seven days post therapy, an egg reduction percentage of $41.89 \%$ at seven days post-therapy and $43.9 \%$ at 14 days posttherapy. The in vitro EHA highlighted a superior efficacy of TBZ (egg hatch percentage at reference concentration being 51.21) compared to ABZ (71.89\%), MBZ (84.46\%) and FBZ (79.22\%), with a minimum risk of anthelmintic resistance. The LDA test revealed the superior efficacy of FBZ (MIC $0.59 \mathrm{mcg} / \mathrm{ml}$ ) and IVM (MIC $0.078 \mathrm{mcg} / \mathrm{ml}$ ), with a minimal risk of inducing parasitic resistance. All in vivo and in vitro tests revealed a limited ABZ efficacy, recommending avoiding the therapy with this substance.
\end{abstract}

Keywords: Anthelmintic, EHA, FECRT, LDA, Pharmacodynamics, sheep, Romania

\section{Introduction}

For treating digestive strongyles in sheep, the more frequently used anthemintics in Romania, are from the benzimidazole and macrocyclic lactones groups. The efficacy of these derivatives are seen by their ovicidal, larvicidal and adulticidal properties, depending on the pharmacologic class (Cristina, 1997; Riviere and Papich, 2009).

The parasitic resistance against anthelmintic medication is an important phenomenon, with real economic implications and having as result a lack of treatment solutions. Often veterinarians apply the antiparasitic treatments without knowing if there is efficacy or if the parasitic population already developed resistance phenomena (Holm et al., 2014). In this context, the aim of the present paper was to evaluate the efficacy of most commonly used anthelmintic treatments in sheep, as well as the evaluation of the resistance occurrence risk against these molecules.

\section{Materials and methods}

The present study was carried out on a population of 602 Tsurcana breed sheep, from which we selected 30 females (4.98\%). The animals were located in a private farm in Sânmihaiu Almașului, Sălaj County, with ages ranging between nine and ten years. They were 
maintained in traditional system, both on pasture and stabled. Five months prior testing, the sheep were dewormed using a fenbendazole based product.

Both in vivo and in vitro assessments were made. In vivo studies were performed by using Fecal Egg Count Reduction Test (FECRT) and evaluating an albendazole-based (ABZ) product used for routine antiparasitic treatments in this sheep population (Taylor et al., 2002; Von SamsonHimmelstjerna et al., 2009).

Faecal samples were obtained and evaluated before the antiparasitic treatment (BT) as well as at 7 and 14 days post-treatment (PT). We used McMaster method to quantify the total number of eggs per gram, parasitic intensity and extensivity BT and PT (Cernea et al., 2010a).

The total egg number per millilitre was determined applying the formula:

Eggs $/ \mathrm{ml}=(1000 \times$ no. eggs per $50 \mu \mathrm{l}) / 50$

Extensivity quantification was obtained by applying the following formula:

E $(\%)=($ No. of positive samples / Total no. of samples) $x 100$

Parasitic intensity quantification was obtained by applying the following formula:

I (EPG) = Total no. of EPG / No. of positive samples, where EPG represents the number of eggs per gram of faeces

The FCERT parasitic reduction percentage calculation was obtained by applying the following formula:

FECRT $=$ [(EPG BT - EPG PT $) /$ EPG BT $] \times 100$, where EPG means eggs per gram of faeces, BT means before treatment, PT means post-treatment (Coles et al., 1992; Von Samson-Himmelstjerna et al., 2009).

In vitro, we used Egg Hatch Assay (EHA) and Larval Development Assay (LDA) for albendazole (ABZ), mebendazole (MBZ), fenbendazole (FBZ), thiabendazole (TBZ), and ivermectin (IVM)(only for LDA) (Von Samson-Himmelstjerna et al., 2009).

EHA results interpretation was obtained by comparing them to those obtained at the reference concentration $(0.15 \mathrm{mcg} / \mathrm{ml})$, as strongyle populations in which eggs hatch in a percent of 50 or above are normally considered resistant (Coles, 1990; Taylor et al., 2002).

For conducting in vitro bioassays, $2 \mathrm{ml}$ well plates were used. The initial solutions consisted in serial dilutions of each substance, from 500 mcg to $0.98 \mathrm{mcg}$ active ingredient $/ \mathrm{ml}$ (a.i. $/ \mathrm{ml}$ ). In each of the first 10 wells we placed $790 \mu$ of distilled water, $200 \mu \mathrm{l}$ of egg suspension and 10 $\mu \mathrm{l}$ of each diluted active ingredient (a.i.). The final testing solutions contained from 5.0 to 0.0098 $\mathrm{mcg}$ a.i. $/ \mathrm{ml}$. We used two controls, $\mathrm{M}_{1}$ consisting of $200 \mu \mathrm{l}$ egg suspension and $800 \mu \mathrm{l}$ distilled water and $\mathrm{M}_{2}$, consisting of $790 \mu$ l distilled water, $200 \mu \mathrm{l}$ egg suspension and $10 \mu \mathrm{l}$ of $\mathrm{HCl}$ solution. In the statistical calculations we used the average obtained from the two controls. After 24 hours in the thermostat at $27^{\circ} \mathrm{C}$, EHA assessment was carried out, by counting both the unembryonated and embryonated eggs as well as the hatched larvae. For the egg hatching percentage, the following formula was applied:

Egg hatching \% $=\left[\left(\mathrm{EE}+\mathrm{L}_{1}\right) /(\mathrm{UE}+\mathrm{EE}\right.$ $\left.+L_{1}\right)$ ] $x$ 100, where $L_{1}$ represents the number of first stage larvae, UE represents the number of unembryonated eggs and EE represents the number of embryonated eggs, (Coles et al., 1992).

For Larval development assay (LDA), we obtained the minimum inhibitory concentrations (MIC) after keeping 14 days the exogenous parasitic forms in contact with the the diluted a.i. at a constant temperature of $27^{\circ} \mathrm{C}$ (Taylor et al., 2002). Larval development percentage was calculated applying the formula:

Larval development \% $=\left[\left(\mathrm{L}_{3} /\left(\mathrm{UE}+\mathrm{L}_{3}\right)\right]\right.$ $x$ 100, where $L_{3}$ represents the number of third stage larvae and UE stands for the number of unembryonated eggs.

Determinations were performed within the Pharmacovigilance Laboratory of Cluj-Napoca Veterinary Medicine Faculty. All gathered data were centralised and statistically interpreted using Anthelmintic Resistance Program (ARP $\left.{ }^{\mathrm{T}}{ }^{\mathrm{m}}\right)$, in order to obtain for each a.i., the following parameters:

- egg hatching percentage at the reference concentration $(0.15 \mathrm{mcg} / \mathrm{ml})$,

- larval development percentage at the reference concentration $(0.15 \mathrm{mcg} / \mathrm{ml})$,

- regression line and and its equation (Y parameters),

- the mean concentration that inhibited hatching in $50 \%$ of the eggs $\left(\mathrm{EC}_{50}\right)$

- minimum inhibitory concentration (MIC)

(Coles et al., 1992; Von Samson-Himmelstjerna et al., 2009; Cernea et al,. 2010b). 
Table 1. The FCERT results obtained for ABZ before the treatment as well as 7 and 14 days PT

\begin{tabular}{cccc}
\hline Sample & EPG BT & EPG 7 days PT & OPG 14 days PT \\
\hline Total EPG & 14800 & 8600 & 8300 \\
\hline Average & 493.33 & 286.67 & 276.67 \\
\hline Standard Deviation & \pm 1008.22 & \pm 268.76 & \pm 446.20 \\
\hline Extensivity (\%) & 66.66 & 80.00 & 70.00 \\
\hline Intensity (EPG) & 740 & 358 & 395 \\
\hline
\end{tabular}

Table 2. Lower limit of the confidence interval and upper limit of the confidence interval for the tested strongyle population

\begin{tabular}{ccc}
\hline Tested parameter & PT - 7 days & PT - 14 days \\
\hline Percent of reduction (\%) & 41.89 & 43.91 \\
\hline LLCI 95\% & -35 & -48 \\
\hline ULCI 95\% & 75 & 79 \\
\hline Note: LLCI. 95\% = lower limit of the confidence interval, ULCI95\%= upper limit of the confidence interval
\end{tabular}

\section{Results and discussions}

The in vivo Faecal Egg Count Reduction Test.

By quantification of strongyle eggs we observed that, before treatment, the sheep presented an average of 493.33 EPG. At seven days PT, the level was considerably reduced, being 286.67 EPG. At 14 days PT we did not find significant changes compared to 7 days evaluation, average EPG count being 276.67 (Tab 1). Parasitic intensity before treatment was $740 \mathrm{EPG}$ with a downward trend at seven days PT (358 EPG) followed by a slight increase at 14 days PT (395 EPG).

The extensivity dynamics for the strongyle population was $66.66 \% \mathrm{BT}$, and surprisingly reached the maximal value of $80 \% 7$ days PT. Therefore the number of positive subjects, in the tested group, was bigger after treatment. At 14 days PT the extensivity level was $70 \%$ this value also being bigger than the one calculated BT. Extensivity and intensity dynamics highlights the reduced effects of $A B Z$ against the tested adult digestive strongyles. This phenomenon is often seen and may be explained by the fact that ABZ acts mostly on the adult active parasitic forms and not on the ones in hypobiosis. After adult parasites being destroyed, the larvae in hypobiosis start a process of rapid transformation into adults and populate the intestinal lumen (Cernea et al., 2010a; Coles, 2005). FECRT highlighted a parasitic reduction percentage of $41.89 \%$ at 7 days PT and $43.9 \%$ at 14 days PT.
Waller (1989) and Coles et al. (1992) consider that resistance phenomenon is present if the reduction percentage is less then $95 \%$ and if the $95 \%$ confidence interval is under $90 \%$ (lower limit of the confidence interval - LLCI 95\%, upper limit of the confidence interval - ULCI 95\%). If one of the two criteria exists, resistance phenomenon is suspected. According to the interpretation sequence for this test, the values are under the minimum accepted value of LLCI95\%, indicating a reduced efficacy of $\mathrm{ABZ}$ against the tested strongyle population. The lower and upper limit of the $95 \%$ confidence interval were also under the maximum accepted limit of $90 \%$ (Tab. 2).

Therefore FECRT results presented the emergence of resistance phenomena for the tested parasitic population. Our results are in accordance with other studies connected to parasitic resistance, this phenomenon being seen in different parasitic species for all animal species and found worldwide (Cristina, 1997; Besier and Love, 2003; Kaplan, 2004; Manninen and Oksanen, 2010; Burgess et al., 2012; Kaplan and Vidyashankar, 2012; Holm et al., 2014).

The in vitro ABZ testing by EHA showed a hatching percentage of $80 \%$ at the reference concentration $(0.15 \mathrm{mcg} / \mathrm{ml})$, indicating reduced ovicidal effects. After statistical analysis of all hatching percentages obtained in all serial dilutions and control samples, the real hatching percentage at the reference concentration was actually $71.89 \%$ even so, way beyond the maximal accepted limit of $50 \% . \mathrm{EC}_{50}$ for $\mathrm{ABZ}$ was $1.26 \mathrm{mcg} /$ 
Table 3. In vitro EHA results obtained for albendazole and thiabendazole

\begin{tabular}{|c|c|c|c|c|c|c|c|c|c|}
\hline \multirow[b]{2}{*}{ Sample } & \multirow[b]{2}{*}{$\begin{array}{l}\text { A.i. conc. } \\
(\mathrm{mcg} / \mathrm{ml})\end{array}$} & \multicolumn{4}{|c|}{$\mathrm{ABZ}$} & \multicolumn{4}{|c|}{ TBZ } \\
\hline & & $\begin{array}{l}\text { No. of } \\
\text { eggs }\end{array}$ & L1 & $\begin{array}{c}\text { Egg } \\
\text { hatching \% }\end{array}$ & $\begin{array}{l}\text { Regression } \\
\text { line equation }\end{array}$ & No.of eggs & L1 & $\begin{array}{c}\text { Egg } \\
\text { hatching \% }\end{array}$ & $\begin{array}{l}\text { Regression } \\
\text { line } \\
\text { equation }\end{array}$ \\
\hline 1 & 5.0000 & 0 & 160 & 100.00 & -23.41 & 120 & 60 & 33.33 & -316.85 \\
\hline 2 & 2.5000 & 40 & 80 & 66.67 & 25.72 & 140 & 100 & 41.67 & -127.13 \\
\hline 3 & 1.2500 & 60 & 100 & 62.50 & 50.28 & 80 & 140 & 63.64 & -32.26 \\
\hline 4 & 0.6250 & 40 & 300 & 88.24 & 62.56 & 140 & 60 & 30.00 & 15.17 \\
\hline 5 & 0.3125 & 40 & 180 & 81.82 & 68.70 & 100 & 120 & 54.55 & 38.88 \\
\hline 6 & 0.1563 & 20 & 80 & 80.00 & 71.77 & 100 & 80 & 44.44 & 50.74 \\
\hline 7 & 0.0781 & 60 & 100 & 62.50 & 73.31 & 140 & 120 & 46.15 & 56.67 \\
\hline 8 & 0.0391 & 240 & 300 & 55.56 & 74.07 & 80 & 100 & 55.56 & 59.63 \\
\hline 9 & 0.0195 & 60 & 440 & 88.00 & 74.46 & 60 & 220 & 78.57 & 61.12 \\
\hline 10 & 0.0098 & 40 & 180 & 81.82 & 74.65 & 60 & 140 & 70.00 & 61.86 \\
\hline $\begin{array}{c}\mathrm{HCl}+ \\
\mathrm{H} 2 \mathrm{O}\end{array}$ & 0.0000 & 30 & 90 & 75.00 & 74.84 & 60 & 170 & 73.91 & 62.60 \\
\hline \multirow[t]{4}{*}{ Total } & & 630 & 2010 & & & 1080 & 1310 & & \\
\hline & \multicolumn{2}{|c|}{ Parameters } & \multicolumn{2}{|c|}{ Hatching \% ref. } & $\begin{array}{c}\mathrm{EC}_{50}(\mathrm{mcg} / \\
\mathrm{ml})\end{array}$ & \multicolumn{2}{|c|}{ Parameters } & $\begin{array}{c}\text { Hatching } \\
\text { \% ref. }\end{array}$ & ${ }_{50}(\mathrm{mcg} / \mathrm{ml})$ \\
\hline & $a$ & -19.65 & & 1.8900 & 1.2600 & -75 . & & 51.2100 & 0.1600 \\
\hline & $\mathrm{b}$ & 74.84 & & & & 62. & & & \\
\hline
\end{tabular}

Note: A.i. conc. = active ingredient concentration, $\mathrm{EC}_{50}=$ mean concentrations that inhibited hatching in $50 \%$ of the eggs, Hatching $\%$ ref. $=$ Hatching percentage at reference concentration of $0.15 \mathrm{mcg} / \mathrm{ml}$

$\mathrm{ml}$ and the regression line had a negative tendency, Ymax parameter having a negative value of -23.41 . These data state the fact that the tested population of digestive nematodes have the tendency to develop adaptative phenomena against ABZ (Tab. $3)$.

For TBZ, EHA results were superior to those obtained in ABZ and MBZ. At the reference concentration, the real hatching percentage was $51.21 \%$, superior to the minimal accepted value. $\mathrm{EC}_{50}$ presented a value of $0.16 \mathrm{mcg} / \mathrm{ml}$, indicating the fact that TBZ is active against strongyle eggs, having an ovicidal effect at very low concentrations. The good TBZ efficacy is also confirmed by the calculation of Ymax parameter which showed a negative trend for the regression line (Ymax $=-316.85)$ (Tab.3).

When testing MBZ, the real hatching percentage at the reference concentration was determined to be $84.46 \%$ (Tab. 4). $\mathrm{EC}_{50}$ for was $-0.54 \mathrm{mcg} / \mathrm{ml}$ indicating that this substance has a really low efficacy, even at the lowest tested dilution $(5 \mathrm{mcg} / \mathrm{ml})$. The regression line equation had the Ymax parameter 324.63. Statistically, the presented data is interpreted by the fact that in order to obtain positive values for $\mathrm{EC}_{50}$ we should have worked with concentrations higher then 5 $\mathrm{mcg} / \mathrm{ml}$, concentrations that cannot be justified and applied as treatments, making this substance not usable for the tested digestive nematode population.

We included FBZ for the in vitro tests because the sheep population was treated with a FBZ based product five months prior the ABZ treatments. EHA results for FBZ showed a hatching percentage of 79.22 at reference concentration indicating a reduced efficacy against the tested parasite population (Tab. 4). The calculated $\mathrm{EC}_{50}$ was -0.69 $\mathrm{mcg} / \mathrm{ml}$ and the regression line had a positive tendency (Ymax = 246.35), indicating a high risk of resistance against this substance. The comparative analysis of the tested parameters in EHA for the four benzimidazoles revealed the superior efficacy of TBZ and a reduced efficacy for ABZ with a very high risk of resistance phenomena. For MBZ and FBZ analysed data showed a very low efficacy, their use not being recommended anymore for the tested population.

The LDA in vitro tests have the advantage of having a prolonged contact (10-14 days) between the anthelmintic substance and the exogenous parasitic forms. For ABZ testing, the presence of L3 larvae was observed starting with the concentration $2.5 \mathrm{mcg} / \mathrm{ml}$, therefore we can state that prolonging the contact time between this substance and the parasites did not have 
Table 4. In vitro EHA results obtained for mebendazole and fenbendazole

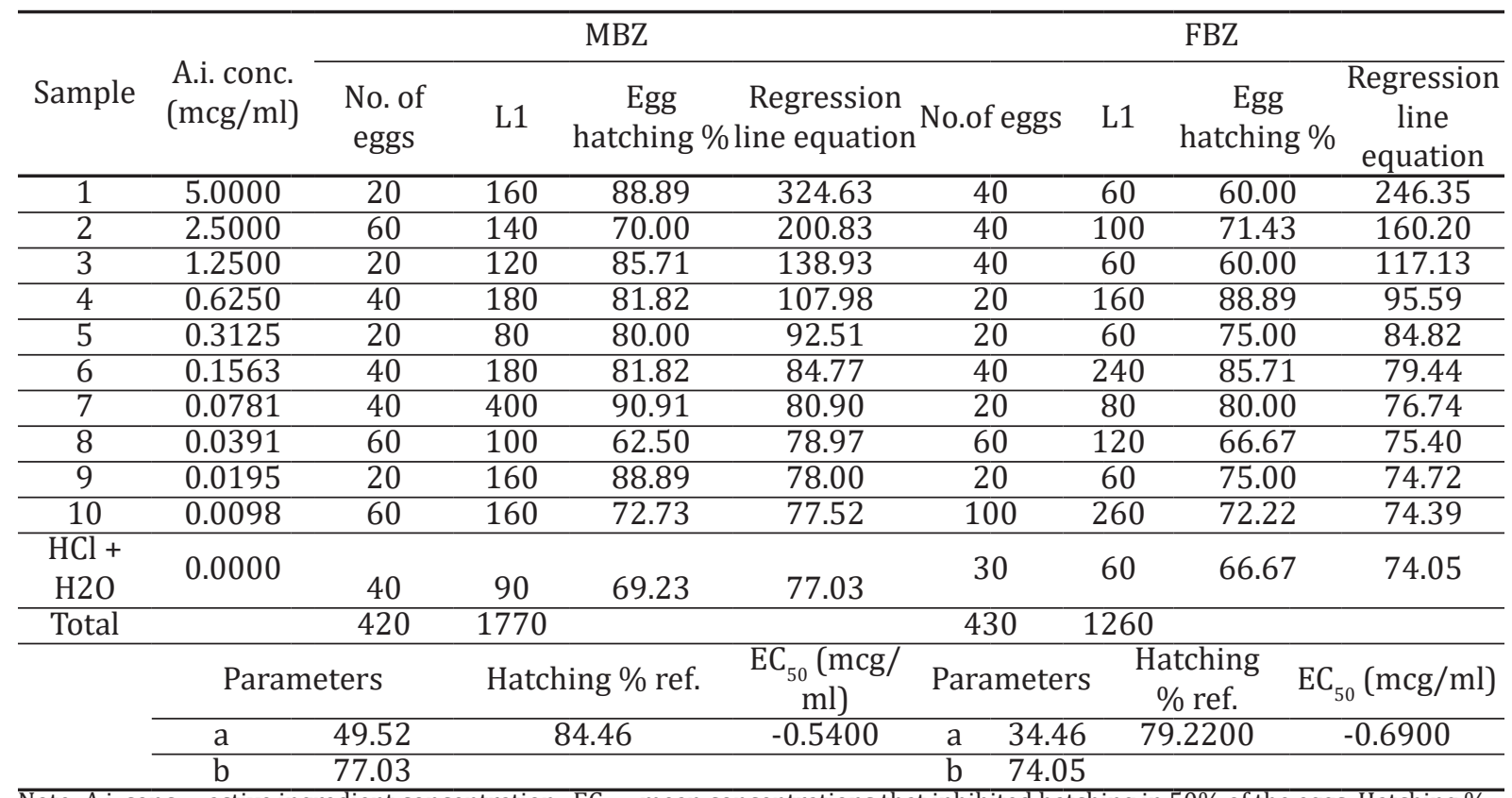

Note: A.i. conc. = active ingredient concentration, $\mathrm{EC}_{50}=$ mean concentrations that inhibited hatching in $50 \%$ of the eggs, Hatching \% ref. $=$ Hatching percentage at reference concentration of $0.15 \mathrm{mcg} / \mathrm{ml}$

Table 5. In vitro LDA results obtained for albendazole and mebendazole

\begin{tabular}{|c|c|c|c|c|c|c|c|c|c|}
\hline \multirow{2}{*}{\multicolumn{2}{|c|}{$\begin{array}{l}\text { A.i. conc. } \\
(\mathrm{mcg} / \mathrm{ml})\end{array}$}} & \multicolumn{4}{|c|}{$\overline{\mathrm{ABZ}}$} & \multicolumn{4}{|c|}{$\overline{\mathrm{MBZ}}$} \\
\hline & & $\begin{array}{l}\text { Eggs } \\
+\mathrm{L} 1 \\
+\mathrm{L} 2\end{array}$ & L3 & $\begin{array}{c}\text { Larval } \\
\text { development } \\
\%\end{array}$ & $\begin{array}{c}\text { Regression } \\
\text { line } \\
\text { equation }\end{array}$ & $\begin{array}{l}\text { Eggs } \\
+ \text { L1 } \\
+ \text { L2 }\end{array}$ & L3 & $\begin{array}{c}\text { Larval } \\
\text { development } \\
\%\end{array}$ & $\begin{array}{l}\text { Regression } \\
\text { line equation }\end{array}$ \\
\hline 5.0000 & 1 & 60 & 0 & 0.00 & -50.29 & 120 & 20 & 14.29 & -50.09 \\
\hline 2.5000 & 2 & 20 & 20 & 50.00 & -14.32 & 100 & 0 & 0.00 & -14.67 \\
\hline 1.2500 & 3 & 20 & 0 & 0.00 & 3.67 & 80 & 20 & 20.00 & 3.05 \\
\hline 0.6250 & 4 & 40 & 20 & 33.33 & 12.67 & 100 & 80 & 44.44 & 11.90 \\
\hline 0.3125 & 5 & 100 & 0 & 0.00 & 17.16 & 120 & 80 & 40.00 & 16.33 \\
\hline 0.1563 & 6 & 20 & 0 & 0.00 & 19.41 & 40 & 20 & 33.33 & 18.55 \\
\hline 0.0781 & 7 & 100 & 60 & 37.50 & 20.54 & 20 & 0 & 0.00 & 19.65 \\
\hline 0.0391 & 8 & 240 & 60 & 20.00 & 21.10 & 100 & 20 & 16.67 & 20.21 \\
\hline 0.0195 & 9 & 120 & 20 & 14.29 & 21.38 & 80 & 20 & 20.00 & 20.48 \\
\hline 0.0098 & 10 & 60 & 40 & 40.00 & 21.52 & 140 & 20 & 12.50 & 20.62 \\
\hline 0.0000 & $\mathrm{H} 2 \mathrm{O}+\mathrm{HCl}$ & 110 & 20 & 15.38 & 21.66 & 30 & 10 & 25.00 & 20.76 \\
\hline \multirow{4}{*}{\multicolumn{2}{|c|}{ Total }} & 890 & 240 & & & 930 & 290 & & \\
\hline & & \multicolumn{2}{|c|}{$\mathrm{MIC}-\mathrm{mcg} / \mathrm{ml}$} & \multicolumn{2}{|c|}{ Parameters } & MIC & $\mathrm{ccg} / \mathrm{ml}$ & \multicolumn{2}{|c|}{ Parameters } \\
\hline & & \multirow{2}{*}{\multicolumn{2}{|c|}{1.3300}} & $\mathrm{a}$ & -14.39 & \multirow{2}{*}{\multicolumn{2}{|c|}{1.1100}} & $\mathrm{a}$ & -14.17 \\
\hline & & & & $\mathrm{b}$ & 21.66 & & & $\mathrm{~b}$ & 20.76 \\
\hline
\end{tabular}

a significant effect on increasing the substance efficacy. The minimum inhibitory concentration (MIC) determined by statistical calculations was $1.33 \mathrm{mcg} / \mathrm{ml}$, the regression line tendency being slightly negative (Ymax $=-50.29)$ (Tab. 5). The limited ABZ efficacy could be explained by the in vivo $\mathrm{ABZ}$ pharmacokinetics. After being administered, ABZ enters the enterohepatic circuit, being transformed in active metabolites, transformation that is not possible when testing the substance in vitro (Riviere and Papich, 2009).

For MBZ, LDA test showed a higher efficacy compared to the one obtained in EHA. even though the first L3 larvae were observed at $5 \mathrm{mcg} / \mathrm{ml}$ concentration, their percentage was low (14.29\%). MIC was $1.11 \mathrm{mcg} / \mathrm{ml}$, better that the one of $\mathrm{ABZ}$ $(1.33 \mathrm{mcg} / \mathrm{ml})$. The superior efficacy of $\mathrm{MBZ}$ in LDA test was also observed when calculating the 
Table 6. In vitro LDA results obtained for thiabendazole and febendazole

\begin{tabular}{|c|c|c|c|c|c|c|c|c|c|}
\hline \multirow[b]{2}{*}{$\begin{array}{l}\text { A.i. conc. } \\
\text { (mcg/ } \\
\text { ml) }\end{array}$} & \multirow[b]{2}{*}{$\begin{array}{c}\text { Sample } \\
\text { no. }\end{array}$} & \multicolumn{4}{|c|}{ TBZ } & \multicolumn{4}{|c|}{ FBZ } \\
\hline & & $\begin{array}{l}\text { Eggs } \\
+\mathrm{L} 1 \\
+\mathrm{L} 2\end{array}$ & L3 & $\begin{array}{l}\text { Larval } \\
\text { develop- } \\
\text { ment \% }\end{array}$ & $\begin{array}{c}\text { Regression } \\
\text { line } \\
\text { equation }\end{array}$ & $\begin{array}{l}\text { Eggs } \\
+\mathrm{L} 1 \\
+\mathrm{L} 2\end{array}$ & L3 & $\begin{array}{l}\text { Larval } \\
\text { develop- } \\
\text { ment \% }\end{array}$ & $\begin{array}{c}\text { Regression } \\
\text { line } \\
\text { equation }\end{array}$ \\
\hline 5.0000 & 1 & 20 & 0 & 0.00 & 64.62 & 40 & 0 & 0.00 & -183.64 \\
\hline 2.5000 & 2 & 100 & 20 & 16.67 & 46.12 & 60 & 20 & 25.00 & -78.07 \\
\hline 1.2500 & 3 & 20 & 0 & 0.00 & 36.87 & 60 & 0 & 0.00 & -25.28 \\
\hline 0.6250 & 4 & 60 & 40 & 40.00 & 32.25 & 40 & 20 & 33.33 & 1.12 \\
\hline 0.3125 & 5 & 80 & 20 & 20.00 & 29.93 & 20 & 20 & 50.00 & 14.31 \\
\hline 0.1563 & 6 & 120 & 20 & 14.29 & 28.78 & 60 & 40 & 40.00 & 20.91 \\
\hline 0.0781 & 7 & 80 & 40 & 33.33 & 28.20 & 20 & 0 & 0.00 & 24.21 \\
\hline 0.0391 & 8 & 80 & 20 & 20.00 & 27.91 & 60 & 20 & 25.00 & 25.86 \\
\hline 0.0195 & 9 & 60 & 40 & 40.00 & 27.76 & 80 & 20 & 20.00 & 26.69 \\
\hline 0.0098 & 10 & 100 & 40 & 28.57 & 27.69 & 40 & 20 & 33.33 & 27.10 \\
\hline 0.0000 & $\begin{array}{l}\mathrm{H} 2 \mathrm{O} \\
+\mathrm{HCl} \\
\end{array}$ & 150 & 50 & 25.00 & 27.62 & 70 & 30 & 30.00 & 27.51 \\
\hline \multirow{4}{*}{\multicolumn{2}{|c|}{ Total }} & 870 & 290 & & & 550 & 190 & & \\
\hline & & $\begin{array}{r}\mathrm{MIC}- \\
\mathrm{r}\end{array}$ & cg/ & \multicolumn{2}{|c|}{ Parameters } & MIC & $\mathrm{cg} / \mathrm{ml}$ & \multicolumn{2}{|c|}{ Parameters } \\
\hline & & \multirow{2}{*}{\multicolumn{2}{|c|}{-3.3900}} & $\mathrm{a}$ & 7.4 & \multirow{2}{*}{\multicolumn{2}{|c|}{0.5900}} & $\mathrm{a}$ & -42.23 \\
\hline & & & & $b$ & 27.62 & & & $\mathrm{~b}$ & 27.51 \\
\hline
\end{tabular}

regression line equation and the Ymax parameter $(-50.09)($ Tab. 5)

Compared to EHA results, TBZ in LDA test presented a limited efficacy against larval development, the maximal percentage of larval development (40\%) being observed at $0.625 \mathrm{mcg} /$ $\mathrm{ml}$ and $0.0195 \mathrm{mcg} / \mathrm{ml}$.

For the LDA, the presence of infecting larvae was observed for all tested TBZ dilutions, excepting $5 \mathrm{mcg} / \mathrm{ml}$ and $1.25 \mathrm{mcg} / \mathrm{ml}$. MIC had a negative value $(-3.39 \mathrm{mcg} / \mathrm{ml})$ and the regression line equation had a positive trend, having a Ymax parameter of 64.62. For this substance, in order to be able to obtain positive values for MIC, we should have worked with concentrations higher than 5 $\mathrm{mcg} / \mathrm{ml}$ (Tab. 6). Due to this low efficacy, nowadays TBZ is rarely used in veterinary medicine.

In vitro LDA testing for FBZ showed surprising results, superiour to those obtained in EHA. MIC was $0.59 \mathrm{mcg} / \mathrm{ml}$, the regression line tendency being negative (Ymax $=-183.64$ ) (Tab. 6). When comparing the results of the two in vitro tests for FBZ we observed a better efficacy for this substance if there is a prolonged contact time and a better larvicidal capacity compared to ovicidal action. As practical applicability of these results, we would recommend that FBZ to be used only if there is the possibility of repeating the treatment at 7-10-14 days interval (Kaplan, 2004).

The last tested larvicidal substance tested in vitro by using LDA was IVM. For this substance $\mathrm{L}_{3}$ larvae were observed in almost all of tested serial dilutions, except $0.15 \mathrm{mcg} / \mathrm{ml}$ and $0.078 \mathrm{mcg} / \mathrm{ml}$. MIC was equal to the one obtained in FBZ (MIC $=0.59 \mathrm{mcg} / \mathrm{ml}$ ), the regression line showing $\mathrm{a}$ negative tendency (Ymax $=-156.81$ ) and a low risk of inducing resistance phenomena (Tab. 7). When comparing all results obtained in LDA, we observed the high efficacy of FBZ and IVM. The minimal risk of inducing resistance phenomena was seen in FBZ followed by IVM, but we must not forget that for ABZ the lack of active metabolites for in vitro testing can offer different results.

The applied in vitro and in vivo assays for ABZ showed a clear correlation between FCERT and the LDA/EHA results. All performed tests showed a low efficacy of ABZ, reason for which we recommend that, from now on, this sheep population to be treated with products based on IVM or FBZ if, for the last one, the treatment can be repeated in 10-14 days (Manninen and Oksanen, 2010). 
Table 7. In vitro LDA results obtained for ivermectin

\begin{tabular}{|c|c|c|c|c|c|}
\hline \multirow{2}{*}{$\begin{array}{l}\text { A.i. conc. } \\
(\mathrm{mcg} / \mathrm{ml})\end{array}$} & \multirow[b]{2}{*}{ Sample no. } & \multicolumn{4}{|c|}{ IVM } \\
\hline & & $\begin{array}{c}\text { Eggs + L1 } \\
+ \text { L2 }\end{array}$ & L3 & Larval development \% & Regression line equation \\
\hline 5.0000 & 1 & 20 & 40 & 66.67 & -156.81 \\
\hline 2.5000 & 2 & 40 & 20 & 33.33 & -65.01 \\
\hline 1.2500 & 3 & 20 & 20 & 50.00 & -19.11 \\
\hline 0.6250 & 4 & 100 & 20 & 16.67 & 3.84 \\
\hline 0.3125 & 5 & 0 & 20 & 100.00 & 15.32 \\
\hline 0.1563 & 6 & 40 & 0 & 0.00 & 21.05 \\
\hline 0.0781 & 7 & 20 & 0 & 0.00 & 23.92 \\
\hline 0.0391 & 8 & 160 & 60 & 27.27 & 25.35 \\
\hline 0.0195 & 9 & 40 & 20 & 33.33 & 26.07 \\
\hline 0.0098 & 10 & 120 & 20 & 14.29 & 26.43 \\
\hline 0.0000 & $\mathrm{H} 2 \mathrm{O}+\mathrm{HCl}$ & 30 & 20 & 40.00 & 26.79 \\
\hline \multirow{4}{*}{\multicolumn{2}{|c|}{ Total }} & 590 & 240 & & \\
\hline & & $\mathrm{MIC}-\mathrm{m}$ & & \multicolumn{2}{|c|}{ Parameters } \\
\hline & & \multirow{2}{*}{\multicolumn{2}{|c|}{0.5900}} & $\mathrm{a}$ & -36.72 \\
\hline & & & & $\mathrm{b}$ & 26.79 \\
\hline
\end{tabular}

\section{Conclusions}

The in vivo FECRT revealed the fact that the tested strongyle population is resistant against ABZ based medication.

In vitro EHA showed a superior efficacy of TBZ and reduced efficacy for ABZ, this last substance having also a maximal risk of inducing resistance phenomena. For MBZ and FBZ a low efficacy was observed;

LDA showed a superior efficacy for FBZ proving that, in this case, a longer contact time can have better effects. The lower risk of inducing resistance phenomena was observed in FBZ followed by IVM.

The applied in vivo and in vitro assays showed a clear correlation between the results, all indicating a reduced efficacy of ABZ.

Acknowledgments. We would like to thank the owner and staff of the farm for their cooperation. This research did not receive any specific grant from funding agencies in the public, commercial or not-for-profit sectors.

\section{References}

1. Besie RB, Love SCJ (2003). Anthelmintic resistance in sheep nematodes in Australia: the need for new approaches. Australian. Journal of Experimental Agriculture, 43, 1383-1391.

2. Burgess CGS, Bartley Y, Redman E, Skuce PJ, Nath M, Whitelaw F, Tait A, Gilleard JS, Jackson F (2012). A survey of the trichostrongylid nematode species present on UK sheep farms and associated anthelmintic control practices. Veterinary Parasitology, 189, 299-307.
3. Cernea M, Cernea L, Cozma V (2010a). Chimiorezistenta la antihelmintice. Ed, AcademicPres, Cluj- Napoca.

4. Cernea M, Cernea Cristina, Carvalho L (2010b). Biomathematical software applicable in pharmacological resistance tests. Scientia Parasitologica, 11 (1): 24-28.

5. Coles GC (1990). Recent advances in laboratory models for evaluation of helminth chemoterapy. Br. Vet. J.,146; 113-119.

6. Coles GC, Bauer C, Borgsteede FHM, Geerts S, Klei TR, Taylor MA, Waller PJ (1992). World Association for the Advancement of Veterinary Parasitology (W.A.A.V.P.) methods for the detection of anthelmintic resistance in nematodes of veterinary importance. Vet Parasitol., 44 (12): $35-44$

7. Coles GC (2005). Anthelmintic resistance - looking to the future: a UK perspective. Research in Veterinary Science, 78, 99-108.

8. Cristina RT (1997). Rezistenţa trichostrongililor la antihelmintice. Ph.D. Thesis. Timişoara Faculty of Veterinary Medicine.

9. Holm SA, Sörensen CRL, Thamsborg SM, Enemark HL (2014). Gastrointestinal nematodes and anthelmintic resistance in Danish goat herds. Parasite 2014, 21, 37, DOI: 10.1051/parasite/2014038.

10. Kaplan RM (2004). Drug resistance in nematodes of veterinary importance: a status report. Trends in Parasitology, 20, 477-481.

11. Kaplan RM, Vidyashankar AN (2012). An inconvenient truth: global worming and anthelmintic resistance. Vet. Parasitol. 186, 70-78.

12. Manninen S, Oksanen A (2010). Haemonchosis in a sheep flock in North Finland. Acta Veterinaria Scandinavica, 52, 19.

13. Riviere JE, Papich MG (2009). Veterinary pharmacology \& therapeutics. Ed. Blackwell publishing, 2009. 
14. Taylor MA, Hunt KR, Goodyear KL (2002). Anthelmintic resistance detection methods. Vet. Parasitol. 103, 183194.

15. Von Samson-Himmelstjerna G, Coles GC, Jackson F, Bauer C, Borgsteede F, Cirak VY, Demeler J, Donnan A, Dorby P, Epe C, Harder A, Hoglund J, Kaminsky R, Kerboeuf D, Kuttler U, Papadopoulos E, Posedi J, Small J, Varady M, Vercruysse J,
Wirtherle N (2009). Standardization of the egg hatch test for the detection of benzimidazole resistance in parasitic nematodes. Parasitology Research, 105, 825-834.

16. Waller PJ (1989). Report of Working Party on Anthelmintic Resistance. SCA Tehnical Series Report no. 28, Ed. Csiro, Cambera, Australia. 